\section{Conflitos éticos no atendimento à saúde de adolescentes}

\author{
Ethical conflicts in health care for adolescents
}

1 Faculdade de Ciências Médicas, Universidade do Estado do Rio de Janeiro, Rio de Janeiro, Brasil.

2 Núcleo de Estudos de Saúde do Adolescente, Universidade do Estado do Rio de Janeiro, Rio de Janeiro, Brasil

3 Faculdade de Enfermagem,

Universidade do Estado do Rio de Janeiro, Rio de Janeiro, Brasil.

Correspondência S. R. Taquette Faculdade de Ciências Médicas, Universidade do Estado do Rio de Janeiro. Rua Gomes Carneiro 34 apto. 802, Rio de Janeiro, RJ 22071-110, Brasil. taquette@uerj.br staquette@globo.com

\section{Abstract}

The goal of this research was to identify ethically conflicting situations experienced by health professionals during health appointments with adolescents in order to create a protocol for action to help professionals make decisions and to protect the clients. The study used an observational cross-sectional method through interviews with health professionals at the Center for Studies on Adolescent Health, Rio de Janeiro State University, to obtain data from cases involving bioethical, ethical, and legal conflicts. Seventy-four professionals reported 149 cases, in which there were 250 conflicts identified through posterior qualitative analysis. The conflicts were interconnected, but for didactic reasons they were mentioned here separately. They included: secrecy and confidentiality, illicit activities, violence, contraception in girls less than 15 years of age, negligence, autonomy, and recording of confidential information on patient medical records. We conclude that there are constant ethical conflicts during health appointments with adolescents, and that bioethics is a useful instrument for solving them. It is also essential to be familiar with the prevailing legislation, to consult pertinent organizations, and to evaluate situations individually.

Bioethics; Medical Ethics; Adolescent
Stella R. Taquette 1,2 Marília Mello de Vilhena ${ }^{2}$ Mariana Maurício Silva 1 Mônica Pereira Vale 3

\section{Introdução}

Na sociedade contemporânea, a adolescência ocupa um espaço e um status decorrentes das mudanças sociais nos últimos anos, que permitiram maior visibilidade e participação dos adolescentes na vida social. Hoje, observamos um prolongamento dessa etapa da vida, evidenciado pela precocidade da puberdade, por um maior tempo de escolarização e uma entrada tardia no mercado de trabalho. Inserindo-se num período longo, de grande crescimento e desenvolvimento, a clientela adolescente que procura os serviços de saúde é muito variada, não homogênea e impõe ações específicas que podem gerar conflitos bioéticos, éticos e legais.

A origem etimológica da palavra ética vem do grego, tem dois significados, que, segundo Pegoraro 1, são complementares entre si. Um deles diz respeito à morada, proteção, e o outro, à formação do caráter. Segundo Lalande 2 em seu Vocabulaire Technique e Critique de la Philosophie, Ética é a ciência que toma por objeto imediato o julgamento de apreciação sobre os atos qualificados bons ou maus. No $D i$ cionário Básico de Filosofia, Japiassú \& Marcondes 3 definem ética como a filosofia que elabora uma reflexão sobre o sentido da vida humana, os fundamentos da obrigação e do dever, a natureza do bem e do mal, concebidos, por exemplo, de modo absoluto e unitário, na ética hipocrática tradicional, com seus princí- 
pios da beneficência e não maleficência. Na tentativa de trazer para a prática a ética filosófica, de unir conhecimento à ação, surgiram as éticas aplicadas na segunda metade do século XX. A Bioética, neologismo cunhado pelo médico norte-americano V. R. Potter em 1970, é considerada a vertente mais desenvolvida das éticas aplicadas. Trata-se de uma nova disciplina que estuda a ética das situações vitais, ou seja, uma nova ética científica da sobrevivência humana que vincula a biologia às humanidades e à preocupação com a qualidade de vida 4 . Sua influência teórica e prática inclui desde situações cotidianas ou persistentes (fome, abandono, exclusão social, má distribuição de recursos escassos, racismo, discriminação dirigida aos excepcionais, aborto, eutanásia etc.) até situações emergentes, de limites ou fronteiriças (novas técnicas reprodutivas, engenharia genética, transplantes, doação de órgãos etc.).

A bioética supera a ética médica por não se limitar exclusivamente ao estabelecimento e à obediência de códigos e preceitos. Seu sentido amplo implica numa ação multidisciplinar que agrega, além das ciências médicas e biológicas, também a Filosofia, o Direito, a Antropologia, a Ciência Política, a Teologia, a Comunicação, a Sociologia, a Economia. Trata-se, sim, da contemplação da questão da "manipulação da vida” através de uma prática interativa num contexto particular que movimenta, de modo concomitante, um saber, uma experiência e uma competência normativa em direção aos problemas que surgem na pesquisa e na clínica. Nos dias de hoje, sua busca consiste numa ação responsável por parte daqueles que devem decidir tipos de tratamento, de pesquisa ou de outras formas de intervenção relativas à humanidade e ao biossistema terrestre. Uma das grandes questões em debate não reside na utilização ou aplicação de novas tecnologias ou nas propostas apresentadas, e, sim, no controle ético, caso a caso e devidamente contextualizado de cada uma das novidades 5 .

Antes de problematizarmos o campo específico da saúde do adolescente, faz-se necessário, por ora, distinguirmos a ética médica deontológica da bioética. A Deontologia funda-se na ciência dos deveres e constitui-se num conjunto de normas indicativas do comportamento de membros de determinado corpo sócioprofissional. Ela também é denominada "ética profissional", e basicamente se limita a dizer o que "deve ser" e o que "não se pode fazer". Apesar de os códigos de ética médica mais recentes, no Brasil e no exterior, começarem a destacar os direitos humanos ao invés de fazerem prevalecer, como os anteriores, posturas mais paternalistas e autoritárias, seus conteúdos não abordam os importantes dilemas éticos que se apresentam no desempenho cotidiano das atividades de saúde 6 .

Na adolescência, verificamos uma incidência significativa de situações conflituosas em que as normas estabelecidas se revelam insuficientes para responder com clareza às nossas interrogações éticas. Um serviço de saúde, por exemplo, pode ser procurado por um adolescente através de sua própria motivação, de seu responsável ou de ambos. Algumas vezes, este não deseja revelar informações confidenciais na presença de seus pais. Para lhe oferecermos a oportunidade de falar de si, é necessário que o atendimento sempre ocorra em dois momentos, no primeiro, com seu responsável e, no segundo, a sós com o profissional. De acordo com o parecer da Sociedade Brasileira de Pediatria de São Paulo 7, a diferença da relação médico-paciente na faixa etária adolescente em relação à da criança é que a primeira deixa de ser uma relação profissional-responsável e passa a ser uma relação profissional-adolescente. Trata-se de uma questão ética a ser discutida, na medida em que o responsável precisa dar autorização para que o menor seja atendido com sigilo e confidencialidade garantidos.

Os princípios éticos no atendimento de adolescentes nos serviços de saúde se referem especialmente à privacidade, à confidencialidade, ao sigilo e à autonomia 8 . Segundo Neinstein 9 , o respeito a esses preceitos encoraja rapazes e moças a procurarem ajuda quando necessário, além de protegê-los da humilhação e discriminação que podem resultar da revelação de dados confidenciais. Pesquisa, realizada por Reddy et al. 10 nos Estados Unidos, mostra que a maioria dos jovens não revelaria certas informações se a confidencialidade não fosse garantida. Em nosso país, o sigilo é regulamentado pelo artigo 103 do Código de Ética Médica (Conselho Federal de Medicina. Brasília; 1988). Em todas as situações em que se caracterizar a necessidade de sua quebra (por exemplo, quando este coloca em risco a sua saúde ou de outrem), o paciente deve ser informado, justificando-se os motivos para essa atitude 11. Entretanto, são freqüentes os conflitos de interesse entre o adolescente $\mathrm{e}$ seus responsáveis. Afastando-se da fixidez das normas deontológicas enquanto padrão de conduta, Leone 12 advoga que tais situações devem ser individualmente estudadas, construindo-se conjuntamente uma "verdade para aquele momento". A corrente casuística, um dos métodos da Bioética, pode aí ser aplicada por ser essencialmente indutiva e empírica, além de considerar a especificidade de cada caso 13 . 
Os diversos marcos legais que definem a adolescência ou o que é ser um adulto aumentam ainda mais as dificuldades no atendimento à saúde dos adolescentes, pois impedem que se tenha clareza em relação aos seus direitos e deveres. Segundo a Organização Mundial da Saúde, a adolescência vai dos 10 aos 20 anos incompletos. Já no Estatuto da Criança e do Adolescente - ECA (Lei $n$. 8069, de 13 de julho de 1990. Brasília: Senado Federal; 1990), ela inicia aos 12 e termina aos 18 anos. Pelo Código Civil Brasileiro (Código de Processo Civil. São Paulo: Editora Revista dos Tribunais; 2003), atinge-se a maioridade aos 18 anos, entretanto, é permitido votar a partir dos 16 anos.

Muitas doenças atuais se devem não diretamente a problemas na esfera da saúde, e, sim, resultam das más condições de vida da população menos favorecida do ponto de vista econômico. São corriqueiros os casos de abandono, de envolvimento com prostituição ou com o tráfico de drogas e, também, ocasiões em que o adolescente sofre algum tipo de violência. Segundo o ECA, em toda situação na qual é identificada a presença de maus-tratos dirigidos ao adolescente, o Conselho Tutelar deve ser acionado. Se assim não proceder, o profissional de saúde estará sujeito a sanções previstas na lei. Porém, freqüentemente este enfrenta situações em que notificar provocará mais prejuízos do que benefícios ao adolescente.

Uma questão relevante e comum na atualidade é a precocidade das relações sexuais na adolescência, o que tem produzido um aumento de gestações e doenças sexualmente transmissíveis. As relações sexuais antes dos 15 anos, segundo o Código Penal Brasileiro (Código de Processo Penal. São Paulo: Editora Revista dos Tribunais; 2000), configuram-se em crime de estupro, previsto no artigo 213, estando a violência presumida na razão da idade da vítima (art. 224, alínea a). Essa lei está totalmente defasada da realidade social atual em que cerca de metade dos adolescentes inicia a atividade sexual anteriormente, segundo apontam algumas pesquisas 14.

A situação de trabalho do jovem brasileiro é crítica. A exploração de crianças e adolescentes tem sido denunciada através de estudos científicos e da imprensa. Os serviços de saúde acabam sendo o espaço no qual os adolescentes podem expor seus apuros e obter ajuda para aliviar suas dores. Segundo o ECA, só é permitido trabalhar a partir dos 16 anos e, sob a condição de aprendiz, dos 14 aos 16 anos.

Toda pesquisa a ser realizada com menores de 18 anos necessita de consentimento por escrito de seu responsável, segundo as Diretrizes e Normas Regulamentadoras de Pesquisa Envolvendo Seres Humanos (Conselho Nacional de Saúde. Resolução 196/96; 1996). A obrigatoriedade deste, muitas vezes, é dificultada pela ausência dos pais ou porque o jovem não lhes revela seus problemas, principalmente quando dizem respeito ao exercício da sexualidade. Alguns autores argumentam que se adolescentes maduros têm o direito de cuidar de si próprios, eles também podem, a princípio, responder questões anônimas e confidenciais sobre sua saúde 15 .

O objetivo deste estudo foi identificar situações do atendimento de adolescentes que envolvem questões bioéticas, éticas e legais para criarmos diretrizes mínimas de atuação que protejam o adolescente e auxiliem o profissional de saúde na tomada de decisões no dia-adia de seu trabalho.

\section{Material e método}

Realizou-se uma pesquisa exploratória, descritiva e analítica de casos que envolvem questões bioéticas, éticas e legais no atendimento à saúde de adolescentes no ambulatório e enfermaria do Núcleo de Estudos da Saúde do Adolescente, Universidade Estadual do Rio de Janeiro (NESA/UERJ). O NESA é uma instituição pública que presta atendimento multidisciplinar a indivíduos de 12 a 20 anos incompletos, a maioria proveniente das camadas pobres da população, em ambulatório e internação hospitalar. $O$ instrumento utilizado foi uma entrevista semi-estruturada, e a população alvo consistiu na equipe profissional multidisciplinar do NESA.

Inicialmente, a estratégia de trabalho foi contactar todos os profissionais que atendem no NESA e sensibilizá-los sobre situações cotidianas que envolvem questões bioéticas, éticas e legais. Em seguida, cada um foi procurado individualmente e indagado sobre a incidência destas em sua prática. Após ser informado e esclarecido sobre os objetivos da pesquisa, ele era convidado a colaborar contando o ocorrido, com garantias de privacidade e sigilo.

A entrevista obedeceu a um roteiro com perguntas abertas e fechadas norteadoras da descrição das situações, facilitando, assim, o seu relato e privilegiando os pontos mais polêmicos e difíceis. De início, colhemos alguns dados profissionais do entrevistado (categoria, ano de formatura, experiência com adolescentes). Posteriormente, perguntamos ao profissional sobre o caso (idade e sexo do adolescente, família, descrição do conflito, conduta tomada, discussão em equipe, sentimento frente ao mes- 
mo). Realizamos um estudo piloto prévio para teste do instrumento. A equipe de pesquisa não teve acesso ao prontuário do paciente, apenas tomou conhecimento das informações ditas pelo profissional. Após a coleta dos dados, estes foram analisados e organizados através de uma leitura crítica, com a construção de categorias classificatórias 16 .

O projeto de pesquisa foi previamente avaliado e autorizado pelo Comitê de Ética em Pesquisa do Hospital Universitário Pedro Ernesto e cumpre os princípios éticos contidos na $D e$ claração de Helsinki. O termo de consentimento livre e esclarecido foi assinado antes da entrevista.

\section{Resultados}

Houve boa receptividade entre os participantes. Todos se mostraram interessados e motivados a debater as questões levantadas pela pesquisa e a conhecer seu desfecho. Foram entrevistados 74 profissionais de nove diferentes categorias: médicos $(32,4 \%)$, enfermeiros $(9,5 \%)$, assistentes sociais $(8,1 \%)$, psicólogos $(9,5 \%)$, dentistas $(2,7 \%)$, fisioterapeutas $(2,7 \%)$, nutricionistas $(2,7 \%)$, fonoaudiólogos $(1,4 \%)$ e auxiliares/técnicos de enfermagem (31,0\%). Houve relato de 149 casos nos quais foram identificados 250 conflitos envolvendo algum questionamento bioético, ético e/ou legal. Os casos eram de adolescentes de ambos os sexos, sendo 60,0\% femininos e 40,0\% masculinos. A idade variou de 10 a 19 anos, sendo a média 14,8 anos. A maioria era proveniente do ambulatório $(79,2 \%)$, sendo apenas $20,8 \%$ pacientes internados.

Após leitura e releitura exaustiva dos casos reportados nas entrevistas, classificamos os conflitos em oito categorias, descritas a seguir:

(1) Conflito relacionado ao sigilo e à confidencialidade na consulta (20,4\%): refere-se a todo caso em que o adolescente foi atendido sozinho e mencionou alguma informação que justificava a quebra de sigilo da consulta, porém o mesmo não estava de acordo. Diziam respeito a: atividade sexual de risco, gravidez, doenças sexualmente transmissíveis, AIDS, aborto, uso de drogas, depressão e suicídio. Exemplos: adolescentes grávidas que se negam a comunicar esse fato aos responsáveis e avisam que vão abortar; adolescentes HIV+ que não aceitam revelar seu diagnóstico à família.

(2) Conflito relacionado à violência contra adolescentes (17,2\%): estão aí incluídos todos os relatos de vítimas de abuso sexual, estupro, violência física, psicológica ou moral. Os exemplos mais comuns são os/as jovens que são violen- tados dentro da própria casa, pelo padrasto. Às vezes, a violência é relatada na consulta, em outras, ela é evidente, mas negada pelo/a adolescente e pela família. Outros casos são de pacientes espancados pelo pai ou namorado.

(3) Conflito relacionado a abandono e maustratos de adolescentes (15,6\%): todas as vezes que o adolescente sofreu danos à sua saúde devido à negligência familiar. Os exemplos mais freqüentes são de adolescentes internados com doenças crônicas incapacitantes (paraplegias, AIDS, drogação) que não recebem visitas da família e alguns casos nos quais ocorre a alta do paciente e ninguém vem buscá-lo.

(4) Conflito relacionado à prática de atividades ilícitas (10,0\%): refere-se a casos de adolescentes que usam e/ou traficam drogas, que se submeteram a abortamento ou praticaram roubo. Exemplos: adolescente foragido da justiça que procura atendimento com médico conhecido a ele vinculado e pede para não ser denunciado e novamente preso; rapazes que consomem drogas ilícitas e/ou trabalham no tráfico; moças que se submetem a aborto clandestino.

(5) Conflito relacionado à atividade sexual em menores de 15 anos $(9,2 \%)$ : refere-se a casos de adolescentes de catorze anos ou menos, sexualmente ativos/as, que buscaram atendimento com queixas relacionadas à prática sexual: contracepção, suspeita de gravidez, DST, abuso etc. Exemplos: adolescentes de 13 anos do sexo feminino que procuram o ambulatório para obter prescrição de contraceptivos, às vezes, sozinhas ou acompanhadas de suas mães. Por vezes, essas adolescentes já moram com o namorado em razão da expulsão de casa pela mãe, após terem "se perdido".

(6) Conflito relacionado à autonomia da/o paciente adolescente $(6,8 \%)$ : refere-se a casos em que a/o adolescente não teve sua autonomia respeitada ou quando esta foi questionada, como situações nas quais os pais não autorizam seu filho a ser atendido sozinho com o profissional, a realizar exames necessários ou trazem o adolescente contra sua vontade. Exemplo: mãe não autoriza a realização de exame antiHIV de seu filho que está internado com forte suspeita de AIDS; mães que trouxeram suas filhas ao médico, à revelia delas, para saberem se eram virgens.

(7) Conflito relacionado ao registro de informações confidenciais e sigilosas no prontuário, relatórios médicos, pedidos de exame etc. $(2,8 \%)$ : ocorreu nos casos em que os profissionais de saúde omitiram dados nos prontuários para evitar a quebra de sigilo das informações e proteger o adolescente. Outras situações reportadas foram de auxiliares/técnicos de en- 
fermagem que, por falta de controle e zelo da instituição de saúde, têm acesso livre à documentação sigilosa dos pacientes. Esses profissionais são freqüentemente expostos a conflitos por não receberem qualquer treinamento para lidar com tais informações. Exemplo: paciente ou seu responsável pergunta ao auxiliar de enfermagem por seu diagnóstico e o profissional revela dados ainda não fornecidos pelo médico; adolescente internada com trauma na região genital, suspeita de abuso sexual pelo pai não confirmada. Essa notícia se espalha por todo o hospital através de conversas entre auxiliares de enfermagem, ficando a jovem estigmatizada, causando-lhe grande sofrimento e à sua família.

(8) Outros conflitos (18,0\%): aí se enquadram os não classificados nas categorias anteriores: ética em pesquisa sobre sexualidade na adolescência, jovem explorado em trabalho insalubre, cliente agredindo profissional, sedução sexual na relação médico-paciente, adolescente com doença crônica e incapacitante, paciente sem recursos para fazer tratamento de doença crônica, profissional de saúde impondo seus valores à conduta de seu cliente. Exemplos: adolescentes portadores de doenças crônicas que não têm recursos para arcar com o custo do tratamento enquanto o poder público não o fornece em tempo hábil; rapaz pobre que trabalha sem nenhuma garantia trabalhista, em situações de risco à sua saúde, com salários aviltantes, sem poder largar o trabalho vital para sua sobrevivência; jovem de 15 anos deseja engravidar, não consegue, procura ajuda médica e o profissional que a atende nega as informações desejadas pela paciente porque a julgou muito nova para ter um filho.

Nas categorias de conflitos relatadas, o profissional não teve facilidade em escolher como agir adequadamente. Quando perguntados sobre o que sentiram perante o caso descrito, os entrevistados revelaram, em sua maioria, sentimentos desagradáveis. As sensações que prevaleceram foram as de impotência, dificuldade, desamparo. Os sentimentos de tristeza, angústia, desconforto e mal-estar também se revelaram constantes. Pouquíssimos casos foram encarados como desafio, realização e interesse.

\section{Discussão}

Os conflitos identificados foram variados e para lidar com eles não basta aos profissionais de saúde recorrer a códigos e leis. O campo da bioética, ética aplicada que descreve e compreende os fatos morais, cria e prescreve normas, constitui-se instrumento útil para resolvê-los, pois, como diz Hottois 17 (p. 124), a "bioética é prática discursiva e discurso prático”. O primeiro passo é o esclarecimento do problema em pauta, seus pressupostos, atores, tipo de conflito. Em seguida, a situação deve ser analisada a partir de referências e formulações éticas do problema, como, por exemplo, normas jurídicas, deontológicas, morais, diretrizes e resoluções. Ao final, escolhe-se a ação ética, respeitando-se prima facie esses princípios e leis. A seguir, discutiremos, em linhas gerais e não em casos específicos, as questões apontadas e classificadas em categorias.

A situação conflituosa mais rotineira no atendimento de adolescentes, a questão do sigilo e confidencialidade na consulta, é aquela que melhor explicita a particularidade dessa etapa da vida de grande crescimento e aquisição progressiva de habilidades. Como ter certeza que o/a adolescente pode sozinho/a arcar com os cuidados de sua saúde? O ECA prevê expressamente que a condição de pessoa em desenvolvimento não retira da criança e do adolescente o direito à inviolabilidade da integridade física, psíquica e moral, abrangendo a identidade, autonomia, valores e idéias, o direito de opinião e expressão, de buscar refúgio, auxílio e orientação. Recomenda-se que a equipe profissional sempre encoraje o adolescente a envolver a família no acompanhamento de seus problemas e que revelar ou não aos pais o conteúdo da consulta é uma decisão a ser tomada juntamente com o próprio. Segundo os pareceres dos Comitês de Bioética das Sociedades Médicas 7, algumas situações justificam a quebra do sigilo da consulta, como é o caso da gravidez, da AIDS. Porém, na prática, nem sempre isso é possível. Às vezes, a família não está presente e nem tem como ser localizada; noutras, ela inexiste ou não é capaz de fornecer qualquer tipo de ajuda. Nesses casos, é necessário que haja recursos públicos que dêem suporte social e emocional a esses pacientes. Os profissionais que os atendem devem estar atentos para identificar essas situações e não desampará-los. À luz da bioética, os profissionais podem considerar eticamente mais eficaz não quebrar o sigilo, mesmo contrariando as recomendações deontológicas, tendo em conta a importância de libertarem-se de um paternalismo que se confunde com beneficência.

A segunda categoria mais freqüentemente identificada, a questão da violência contra adolescentes, não é uma particularidade da adolescência. Ela é fruto da violência estrutural de nossa sociedade, aqui entendida como aquela que restringe o acesso da maioria das pessoas 
aos direitos básicos. Esta se apresenta em outras parcelas da população também em situação de menor poder, como é o caso de mulheres, idosos, negros e homossexuais 18. O ECA promoveu uma grande mudança de olhar em relação a crianças e adolescentes. Estes passaram a ser sujeitos de direitos e não somente agentes passivos de proteção e cuidados. De acordo com esta lei, os profissionais que os atendem são obrigados a notificar ao Conselho Tutelar os casos de maus-tratos. Denunciar ou não foi a principal dificuldade reportada pelos profissionais, já que, em algumas ocasiões, isso pode não resultar em benefício concreto ao adolescente. Essa é uma questão que não pode ser minimizada, pois, segundo a ABRAPIA (Associação Brasileira Multidisciplinar de Proteção à Infância e Adolescência) 19 , o número de comunicações de abuso sexual a menores no Estado do Rio de Janeiro é recorde e os casos comumente ocorrem no ambiente familiar, sendo o pai e, em seguida, o padrasto os principais abusadores. Para a promotoria da infância e juventude 20 , é inacreditável o índice de impunidade do agressor de crianças e adolescentes. Esta sugere a criação de delegacias especializadas na investigação de crimes contra eles para garantir-se um espaço físico específico e centralizado para o atendimento das vítimas. Não interessa às autoridades judiciárias, a princípio, apurar a autoria do delito no caso de agressão contra adolescentes. É necessário amparar a vítima, encontrar meios de superar o trauma, localizar, na família, alguém que possa proteger $\mathrm{o} / \mathrm{a}$ adolescente contra o agressor, eliminando o fator de risco. O ECA representa um avanço em relação aos direitos de crianças e adolescentes, porém, segundo Paiva 21, uma das causas da não diminuição da violência consiste na ausência de políticas públicas e comunitárias, tanto de ordem preventiva como terapêutica, que possam garantir aos jovens os seus direitos fundamentais. Se, ao analisar caso a caso, a denúncia da violência, por vezes, revela-se inoperante, cabe, no entanto, sempre termos como horizonte o desejo individual livre e soberano em que se pauta a bioética, desde que este não invada a liberdade e os direitos do outro.

A terceira categoria mais comum, a negligência e o abandono, esteve relacionada à pobreza, na maior parte dos casos. São famílias desestruturadas, pobres, vítimas da violência estrutural da sociedade, que, devido a tanto desamparo, não conseguem cuidar de seus membros e ampará-los. Os serviços de saúde devem conhecer as políticas públicas que oferecem cuidado a esses menores e a suas famílias, acio- ná-las sempre que preciso for, baseando-se na eqüidade, marco conceitual da bioética que permite resolver parte razoável das distorções na distribuição da saúde ao aumentar as possibilidades e a qualidade de vida de importantes parcelas da população. Trata-se, sim, do reconhecimento de necessidades diferentes, de sujeitos também diferentes para atingir direitos iguais. A atenção diferenciada para os desiguais visa à igualdade como ponto de chegada da justiça social, referencial dos direitos humanos, no qual o passo seguinte é o reconhecimento da cidadania. Segundo Garrafa 5, o conceito de eqüidade constitui-se na palavra-chave em saúde para o início do século XXI.

Na categoria das práticas de atividades ilícitas como aborto, consumo e tráfico de drogas, cada situação deve ser avaliada individual e criteriosamente, para que não haja prejuízo para o adolescente ou para a sociedade. Vivemos um período de crise social e econômica em que os jovens das camadas menos favorecidas da população têm pouca ou nenhuma perspectiva de vida, o que os torna alvo fácil de cooptação em atividades delituosas. Nessa categoria, os adolescentes são também vítimas de violência estrutural da sociedade, como na anterior. Na maioria dos casos relatados, nenhuma medida legal foi tomada. O paciente era tratado do seu problema de saúde, independente do ato ilegal praticado. É indispensável que serviços de saúde que atendem adolescentes tenham um canal de comunicação direta com o poder judiciário para que medidas mais pertinentes e eficazes sejam tomadas. $\mathrm{O}$ conceito de eqüidade também nesses casos deve ser contemplado, associando-se ao tema da responsabilidade (individual e pública) e da justiça, a fim de conseguirmos fazer valer o valor do direito à dignidade e à saúde.

A atividade sexual antes dos 15 anos é outra questão polêmica. Apesar de os estudos epidemiológicos evidenciarem uma diminuição da idade de início de intercursos com envolvimento genital entre os jovens, além de um maior número de gravidezes na adolescência, temos um código penal que descreve essa prática sexual como fruto de violência, em razão da baixa idade da vítima. Os médicos, procurados por adolescentes no intuito de obter aconselhamento sobre planejamento familiar e receitas de pílulas anticoncepcionais, sentem-se amedrontados com as possíveis repercussões legais desse ato. Segundo Saito 22, no caso da prescrição de contraceptivos para menores de 15 anos, o ECA se confronta, em seu artigo 103, com o código penal e, a seu ver, o supera, na medida em que este preconiza que os direitos básicos 
de saúde e liberdade predominam sobre qualquer outro que possa prejudicá-lo. Portanto, na avaliação de saúde, o médico junto à sua paciente pode decidir pela contracepção se assim o considerarem como a melhor ação em prol da saúde da própria. Essa opinião é corroborada por outros profissionais com experiência em adolescentes, que debateram esse tema em fórum realizado em novembro de 2002, no Instituto da Criança, Universidade de São Paulo. Segundo as diretrizes da Sociedade Brasileira de Pediatria (SBP) e Federação Brasileira das Sociedades de Ginecologia e Obstetrícia (FEBRASGO), a prescrição de métodos anticoncepcionais para moças com menos de 14 anos deverá levar em conta a solicitação delas, respeitando-se os critérios médicos de elegibilidade, independentemente da idade, e isso não constitui ato ilícito por parte do médico. Na atenção à menor de 14 anos sexualmente ativa, a presunção de estupro deixa de existir, frente ao conhecimento que o profissional possui de sua não ocorrência, a partir da informação da adolescente e da avaliação criteriosa do caso, que deve estar devidamente registrada no prontuário médico. Porém, não devemos, ao receber uma jovem menor de 15 anos em busca de contraceptivos, ser simplistas nessa avaliação. Apesar de a precocidade das relações sexuais, na atualidade, ser encarada como algo natural, do risco existente de uma gravidez indesejada e de quase sempre a adolescente negar que tenha se relacionado sexualmente contra sua vontade, o profissional de saúde deve contextualizar essa jovem e, com sua maturidade, avaliar cada caso. Pensar a sexualidade humana pelo prisma de uma ética aplicada, de uma bioética implica admitir que nossos corpos não são independentes da rede discursiva em que estamos inseridos nem da rede de trocas que estabelecemos. Eles são efeito dos discursos que dão consistência simbólica à vida social. Isso se exemplifica comumente quando vemos pais negligentes que até estimulam suas filhas a iniciarem um envolvimento genital para se livrarem da responsabilidade do cuidado e do sustento dessas jovens, expulsando-as de casa para morar com o namorado, assim que revelam terem perdido a virgindade.

Na sexta categoria de conflito, a competência para o autocuidado na adolescência é colocada em cheque. Muitos profissionais advogam que os adolescentes não devem ter autonomia, ou seja, as decisões sobre sua saúde precisam passar pelo crivo de seus pais. Entretanto, na prática, observa-se que nem sempre os atos dos adultos responsáveis incorrem em benefício para os menores. Se isso fosse verda- de não haveria leis para proteger os menores do pátrio poder. A partir dos 15 anos, em geral, os indivíduos são capazes de exercer sua autonomia. Silber 23 refere que a adolescência é um período da vida de individuação e de troca de funções: "a de ser nutrido para a de prover a nutrição”. Essa categoria é semelhante à primeira, e ambas podem ser tratadas sob uma mesma ótica.

Na sétima categoria, ficou clara a importância de estar-se atento à não revelação em reuniões e bate-papos informais entre profissionais de saúde de informações registradas ou não em prontuários e fichas médicas, pois sua divulgação pode causar danos irreparáveis aos pacientes. Cabe salientar a necessidade de uma cautela efetiva em relação a toda documentação do usuário, visto que ela é de sua propriedade, e o hospital tem a obrigação legal de manter sua guarda. Os administradores de estabelecimentos de saúde compartilham a responsabilidade com os profissionais na manutenção correta e completa da documentação das atividades ocorridas com o paciente. A privacidade das informações é um dever profissional e institucional 6. Chamou-nos a atenção nessa categoria a falta de zelo com os prontuários, assim como a facilidade com que várias pessoas tiveram acesso aos mesmos. Os médicos e administradores deste estabelecimento deveriam ser mais criteriosos quanto a seu desempenho, além de fornecerem aos profissionais de enfermagem treinamento específico para lidar no enfrentamento de questões. Em geral, a equipe se sente verdadeiramente perdida e desamparada quanto ao agir. Porém, em casos extremos nos quais torna-se impossível o diálogo entre os profissionais, é indispensável que o agir concreto se paute nos limites mais avançados possíveis da ética, incorporando, sim, o tema da tolerância, mas não esquecendo os limites da responsabilidade.

$\mathrm{Na}$ oitava categoria, foram englobados todos os outros conflitos, menos freqüentes, porém igualmente importantes, que também devem ser debatidos e refletidos. A questão da exploração do trabalho dos adolescentes, por exemplo, está diretamente relacionada à situação de pobreza e violência estrutural da sociedade. Estes se articulam com os impasses relacionados à falta de recursos governamentais para a compra de medicamentos. A saúde pública ineficiente limita a autonomia, pois o paciente não pode escolher o melhor tratamento já que o sistema público não o oferece 24 . O artigo 7o do ECA é taxativo quando estabelece que a criança e o adolescente têm direito à proteção à vida e à saúde. Ele define expressamen- 
te as responsabilidades pela garantia deste ao dispor a incumbência do Poder Público para fornecer gratuitamente medicamentos, próteses e outros recursos relativos ao tratamento, habilitação ou reabilitação àqueles que necessitarem 25. Outros conflitos apresentados dizem respeito à relação médico-profissional, às emoções suscitadas por esse relacionamento. Para aqueles que trabalham com adolescentes, estes últimos podem a eles apresentar-se como provocadores de suas defesas 26 . $\mathrm{O}$ ato ético requer uma auto-avaliação permanente a fim de manter-se verdadeiramente a serviço do paciente.

\section{Considerações finais}

Os conflitos éticos identificados neste estudo demandam aos profissionais de saúde atitudes que não encontram respaldo na ética hipocrática tradicional, hegemônica na medicina desde a antiguidade até os anos sessenta. Hoje, porém, tais princípios antigos da beneficência e não maleficência, que elaboram os conceitos de bem e mal em si, não são suficientes para responder às novas questões. Os preceitos de autonomia e justiça se contrapõem à ética tradicional. Foi nesse contexto de questionamentos éticos que surgiu a Bioética, e, dentre as suas correntes, a principialista (a teoria dos quatro princípios: beneficência, não maleficência, respeito à autonomia e justiça) pode ser vista como abrangendo a maioria das questões éticas que se aplicam aos cuidados de saúde. Nesse campo, este modelo de análise dos dilemas morais 27 não segue prescrições absolutas, e, sim, princípios prima facie, ou seja, admite exceções e sua transgressão justifica-se em situações em que há conflitos entre os preceitos. Transportando-o para a área da saúde do adolescente, ele se revela de grande auxílio no enfrentamento de situações dilemáticas.

Em conclusão, os conflitos apontados são rotineiros e graves. No atendimento à saúde dos adolescentes, os profissionais devem: contextualizar seus pacientes; avaliar, na ocasião, as competências dos mesmos; conhecer leis e estatutos; documentar cuidadosamente as informações; consultar o Ministério Público e as Sociedades Legais; compartilhar e discutir o caso em equipe para que haja maior proteção dessa população adolescente e mais segurança por parte de quem a atende. A reflexão bioética, como já o dissemos, baseada na multidisciplinaridade e no respeito ao pluralismo moral social, ao questionar parâmetros secularmente estagnados, muito pode nos ajudar no âmbito da saúde do adolescente, e, junto a este último, ir a cada momento e em cada caso estabelecendo novos referenciais éticos, através do abandono de regulamentações imperiosas e cristalizadas.

\section{Resumo}

O objetivo desta pesquisa foi identificar situações eticamente conflituosas, vivenciadas por profissionais de saúde no atendimento de adolescentes, para se criar diretrizes mínimas de atuação que auxiliem os primeiros na tomada de decisões que protejam essa clientela. Utilizou-se um método observacional, transversal através de entrevistas com profissionais do Núcleo de Estudos de Saúde do Adolescente, Universidade do Estado do Rio de Janeiro, para se colher dados sobre casos atendidos em que foram identificados conflitos bioéticos, éticos ou legais. Setenta e quatro profissionais relataram 149 casos, nos quais, através de análise qualitativa posterior, identificou-se 250 conflitos. Estes amiúde se articulavam entre si, mas, por motivos didáticos, foram ordenados em separado e dizem respeito a: sigilo e confidencialidade, prática de atividades ilícitas, violência, contracepção em menores de 15 anos, negligência, autonomia e registro de informações confidenciais no prontuário. Concluímos que os conflitos éticos no atendimento de adolescentes são constantes e para solucioná-los a bioética se apresenta como um útil instrumento. Além disso, é preciso conhecer leis e códigos, consultar os órgãos competentes e avaliar situações em particular, não seguindo prescrições absolutas.

Bioética; Ética Médica; Adolescência 


\section{Colaboradores}

S. R. Taquette contribuiu na concepção teórica, coleta e análise dos dados, elaboração e redação final do manuscrito. M. M. Vilhena colaborou na análise dos dados e redação final do manuscrito. M. M. Silva e M. P. Vale participaram na coleta de dados e revisão bibliográfica.

\section{Referências}

1. Pegoraro O. Ética e bioética: da subsistência à existência. Petrópolis: Vozes; 2002.

2. Lalande A. Vocabulaire technique et critique de la philosophie. Paris: Presses Universitaires de France; 1985.

3. Japiassú H, Marcondes D. Dicionário básico de filosofia. Rio de Janeiro: Jorge Zahar Editor; 2001.

4. Almeida JLT, Schramm FR. Paradigm shift, metamorphosis of medical ethics, and the rise of bioethics. Cad Saúde Pública 1999; 15 Suppl 1:1525.

5. Garrafa V. Bioética e manipulação da vida. In: Novaes $\mathrm{A}$, organizador. Homem-máquina. São Paulo: Companhia das Letras; 2003. p. 213-25.

6. Fortes PAC. Ética e saúde. São Paulo: EPU; 1998.

7. Sociedade de Pediatria de São Paulo. Aspectos éticos no atendimento médico do adolescente. Rev Paul Pediatr 1999; 17:95-7.

8. Fortes PACF, Sacardo DP. Ética na assistência à saúde do adolescente e do jovem. In: Ministério da Saúde, organizador. Cadernos juventude, saúde e desenvolvimento. Brasília: Ministério da Saúde; 1999. p. 147-61.

9. Neinstein LS. Understanding legal aspects of care. In: Neinstein LS, editor. Adolescent health care: a practical guide. Baltimore: Williams \& Wilkins; 1996. p. 150-5.

10. Reddy D, Fleming R, Swain C. Effect of mandatory parental notification on adolescents girls' use of sexual health care services. JAMA 2002; 288: 710-4.

11. Oselka G, Troster EJ. Aspectos éticos do atendimento médico do adolescente. Rev Assoc Med Bras 2000; 46:306-7.

12. Leone C. A criança, o adolescente e a autonomia. Bioética 1998; 6:51-4.

13. Schramm FR. A autonomia difícil. Bioética 1998; 6:27-37.

14. Taquette SR, Vilhena MM, Paula MC. Doenças sexualmente transmissíveis e gênero: um estudo transversal com adolescentes no Rio de Janeiro. Cad Saúde Pública 2004; 20:282-90.

15. Strasburger VC. Parenteral permission in adolescent health research. J Adolesc Health 1998; 22:362.

16. Gomes R. A análise de dados em pesquisa qualitativa. In: Minayo MCS, organizador. Pesquisa so- cial: teoria, método e criatividade. Petrópolis: Editora Vozes; 2001. p. 67-80.

17. Hottois G. Bioéthique. In: Hottois G, Missa JN, editors. Nouvelle encyclopédie de bioéthique. Bruxelles: De Boeck Université; 2001. p. 124-31.

18. Cruz Neto O, Moreira MR. A concretização de políticas públicas em direção à prevenção da violência estrutural. Ciênc Saúde Coletiva 1999; 4:33-52.

19. Associação Brasileira Multiprofissional de Proteção à Infância e à Adolescência. Abuso sexual contra criança e o adolescente. Petrópolis: Autores \& Agentes \& Associados; 1997.

20. Bezerra SC. Exploração e o abuso sexual de crianças e adolescentes. http://www.abmp.org.br/ publicacoes/portal_ABMP_Publicacao_635.doc (acessado em 16/Mar/2004).

21. Paiva JD. Violência, juventude e exclusão social. http://www.abmp.org.br/publicacoes/portal_AB MP_Publicacao_414.doc (acessado em 16/Mar/ 2004).

22. Saito MI, Leal MM. Aspectos éticos da contracepção na adolescência. Rev Assoc Med Bras 2003; 49:234.

23. Silber TJ. Aspectos éticos da relação médico-paciente adolescente. Adolesc Latinoam 2002; 3(2). http://ral-adolec.bvs.br/scielo.php?script= sci_arttext\&pid=S1414-71302002000200004\&lng= es\&nrm=iso\&tlng=pt.

24. Fabro L. Limitações jurídicas à autonomia do paciente. Bioética 1999; 7:1-17.

25. Bezerra SC. Dever do Estado e direitos do adolescente na assistência à saúde. http://www.abmp. org.br/publicacoes/portal_ABMP_Publicacao_ 536.doc (acessado em 16/Mar/2004).

26. Sutton A. Authority, autonomy, responsability and authorisation with specific reference to adolescent mental health practice. J Med Ethics 1997; 23:26-31.

27. Loch JA. Como analisar conflitos em bioética clínica. In: Urban CA, organizador. Bioética clínica. Rio de Janeiro: Revinter; 2003. p. 48-54.

Recebido em 16/Ago/2004

Versão final reapresentada em 19/Jan/2005

Aprovado em 04/Mai/2005 